Supposing the air rises to one thousand feet, it will there be cooled to 12 ; then descending, as it passes over the range, it will at first $(F G)$ warm as slowly as it cooled, until all the cloud that it carries is dissolved; the rest of the descent has a faster warming $(G H)$, and the ground is reached with a temperature of about $43^{\circ}$, or $8^{\circ}$ warmer than when the ascent began.

These figures are not precise, as the diagram is rather hastily constructed from Hertz's plate; but they serve to show how much greater a change is produced by the descent of the upper air than by the evolution of latent heat in a transmontane wind. The approach of the line of summer temperature $\left(S S^{\prime}\right)$ to parallelism with the adiabatics also illustrates how much fainter the foehn must be in summer than in winter.

The following quotation from Espy's 'Fourth meteorological report' (1857) is of interest in this connection: "It is known that air, in passing over high mountains..... is twenty or thirty degrees warmer than the atmosphere is at the same height over plains, because in passing over them it has the latent caloric in it, just evolved by the condensation of the vapor on the windward side." "Air can never come down from a great height without being very dry when it reaches the surface of the earth." "At the time of this hot south wind, there may be a great rain taking place on the other side of a mountain to the south of the observer, sending its bot air over above, and radiating its abnormal heat down, and even bringing some of the hot air down the slope on the north, which would be felt there as an excessively hot, dry air." He also quotes Lopoy's mention of a warm south-west wind at Fort Simpson, east of the Rocky Mountains in British America. and applies the above explanation to it (pp. 146, 147, 151).

Cambridge, Jan. 12.

W. M. Davis.

\section{The claimed wheat and rye hybrid.}

There is very slight botanical distinction between the wheat and rye genera, and hence we could scarcely select two genera between which we should more readily expect, a priori, a success in hybridization. The question, however, is, Has such a hybridization been effected? Mr. Charles Barnard, who scarcely can speak as a botanist, states in the January Century, p. 47\%, that it has taken place. As one who has carefully studied the published claims, and who has also visited the growing plants upon which the result is claimed, I must beg to dissent. Without opportunity for a careful and thorough examination of the various plants produced, I dare not affirm that such a hybridization has not been effected; yet I do dare affirm that the evidence adduced is insufficient to establish the fact, and is sufficient to establish grave doubts.

What are the facts? The flowers of the Arm. strong wheat were treated with pollen from rye. A number of variables were produced from the resulting seed, which, without careful botanical investigation, have been pronounced hybrids. These figures were published in the Rural New-Yorker of Aug. 30, 1884 .

Lindley distinguishes rye from wheat by its nar. row glumes, and constantly twin narrow florets with a membranous abortion between them. In the drawings referred to, the glumes in all the figures are drawn broader than in the rye. In four of the figures the spikelets are distinctly those of a common wheat. In the fifth figure - the one called by $\mathrm{Mr}$. Carman "a distinct grain, neither wheat nor rye, and as different from either as wheat is from rye, or rye from wheat"- we must look for the hybrid, if at all. This plant, so far as can be indistinctly made out from the figure, has its spikelet solitary on each notch of the axis, with two nearly equal glumes : and the outer pale of each floret has at the top either a notch or angle on each side of the terminal point or awn, - all the distinguishing characters of the genus Triticum. It has not the narrow glumes nor the constantly twin narrow florets which are peculiar to rye.

What do these figures resemble, if not rye? Judging by comparison of pictures, his No. 335 is close to the Froment de Saumur; his No, 336, to Froment Pictet; his No. 337, to Froment de Naples; his No. 338, to Froment blanc de Flandre; his No. 339, the supposed hybrid, to Froment de Pologne compact, all, as figured by Heuze, in the form of the head. I do not mean to say by this that they are these varieties, for the material for judgment does not admit of such close comparison; but I refer to these varieties, and those represented by Mr. Carman's figures, as representing like types of head.

We do not question the attempt at a cross. The variability effected is indication of the influence of a foreign pollen. We can explain the appearances, however, by an hypothesis. Under the stimulus of the rye pollen, atavism has resulted, whereby varieties dormant in the Armstrong wheat have made their appearance; and to those unfamiliar with foreign varieties, whose type appears in the progeny, the seedlings produced seem as if novelties, the unfamiliar Blé de Poland being little known in this country.

The whole subject is, however, too interesting a one to allow to pass without comment such statements as the Century article contains, and it is to be hoped that at some time a botanist expert in agriculturai botany may have opportunity to investigate a series of these specimens.

Genera, N.Y., Jan. 6 .

E. Lewis Sturtevant.

\section{Stepniak's 'Russia under the tzars.'}

Will you kindly permit a few words of reply from one of your English readers to M. Woeikof's letter on p. 478 of your issue for Nov. 27, 1885 ?

We in the old country, who are watching with deep interest the struggle for freedom now going on in Russia, do not attach so much importance as your correspondent seems to think we should. to Stepniak's personal share in the conflict: indeed, we do not even care to inquire about it. The important point for us is the accuracy of the facts he has brought forward. If true, they place the Russian government outside the pale of civilization, and deprive it of all right to appeal to civilized Europe against any act in which the wrath and despair of its subjects may find vent. If false, they can easily be disproved. Stepniak has plainly stated names, dates, and sources of information; his book has now been for a year before the public; and he has reiterated his charges through the leading organ of the English press. If the Russian government is maligned, why does it take no steps to disprove his statements?

But whilst Stepniak's allegations are confirmed by 